\title{
Fate of Neoaortic Valve in Patients undergoing Arterial Switch Operation for Transposition of Great Arteries
}

\author{
Sachin Talwar ${ }^{1}$, Anish Gupta ${ }^{1}$, Vishnubhatla Sreenivas ${ }^{2}$, Shiv Kumar Choudhary ${ }^{1}$ and Balram \\ Airan $^{1}$ \\ ${ }^{1}$ Department of Cardiothoracic and Vascular Surgery, All India Institute of Medical Sciences, New Delhi, India
}

${ }^{2}$ Department of Biostatistics, All India Institute of Medical Sciences, New Delhi, India

Received: 30 May, 2017; Accepted: 11 July, 2017; Published: 20 July, 2017

*Corresponding author: Sachin Talwar, Professor, Department of Cardiothoracic and Vascular surgery, All India Institute of Medical Sciences, New Delhi - 10029, India, Tel- 91-9868398136, Fax-91-11-26588663; E-mail: sachintalwar@hotmail.com

\begin{abstract}
Objectives: The aim of this study was to evaluate the incidence of neo-aortic regurgitation (AR) after arterial switch operation (ASO) and the associated risk factors.

Methods: Retrospective review of records of 289 patients undergoing arterial switch operation from 2005 to 2015 was performed along with echocardiographic examination of neo-aortic valve, ventricular function and associated risk factors.

Results: Mean weight at operation was $3.5 \pm 0.25 \mathrm{~kg}$. 150 patients had associated ventricular septal defect (VSD) out of which 19 were Taussig-Bing type and remaining 139 patients had intact ventricular septum. At last follow up (4.82 \pm 3.1 ; Range 1-11 years), 35 patients $(12.1 \%)$ had developed AR; 24 had trivial AR and 10 had mild AR while only 1 had moderate AR. Freedom from intervention for aortic valve after ASO was $100 \%$ after 10 years. On univariate logistic regression analysis, complex transposition of great arteries (TGA) (presence of VSD, associated abnormalities like TAPVC, arch anomalies) was found to be a risk factor for AR. Presence of left ventricular outflow tract obstruction (LVOTO), pre-operative Aortapulmonary artery size discrepancy and abnormal coronary artery anatomy were also significant risk factors for neo-aortic regurgitation. On multi-variate logistic regression analysis, presence of VSD, LVOTO, abnormal coronary artery anatomy and Aorta - pulmonary artery size discrepancy were significantly associated risk factors for neo-aortic regurgitation.
\end{abstract}

Conclusions: In our experience, incidence of AR after ASO remains low. Development of AR is related to presence of complex TGA, pre-operative aorta pulmonary size discrepancy and abnormal coronary artery anatomy.

Keywords: Transposition of great arteries; Arterial switch operation; Aortic regurgitation

\section{Introduction}

Since Jatene et al first described arterial switch operation (ASO), it has become the operation of choice for transposition of great arteries in neonates and infants with excellent early and midterm outcomes [1]. It avoids the long term complications of atrial switch like systemic Atrioventricular valve regurgitation and right ventricular failure by achieving anatomical correction. However, long-term concerns with the ASO are coronary obstruction, left ventricular dysfunction and right ventricular outflow tract obstruction [2-4]. Following ASO, the native pulmonary valve and root become the neo aortic valve and root. Although aortic valve and pulmonary valve have similar characteristics at birth, aortic valve develops more collagen and elastic fibers with time due to the high resistance offered by systemic circulation. But when the pulmonary valve is placed in the position of aortic valve, it poses undue stress on it making it susceptible to deterioration with time. Also, pre-operative discrepancy between aorta and pulmonary artery at the time of ASO and methods to correct it, can increase the prevalence of neo-aortic regurgitation (AR) in future.

In a study by Nogi, et al AR affects as many as 30\% patients six years after undergoing the ASO. Progressive increase in AR has also been reported by Imamura et al, Yoshizumi et al, and Schwartz et al [5-8].

Conflicting results have been reported by Losay, et al, who noted a lower incidence of AR with time with a similar period of follow up. In a study by Walter et al, AR was not rare after ASO, but was stable without progressive intensity; If trivial AR was excluded, it was present only in $0.9 \%[9,10]$. However, severe AR and the need for aortic valve replacement (AVR) were rare.

Various risk factors have been associated with development 
of neo-aortic regurgitation. In a study by Formigari et al, the trapdoor type of coronary artery re-implantation is associated with an increased risk of valvular dysfunction, possibly because of distortion of the sino-tubular junction geometry [11]. Previous pulmonary artery band and a bicuspid pulmonary valve have also been incriminated in increased development of neoaortic regurgitation by Gibbs et al and Keane et al respectively $[12,13]$. Another common association has been the presence of a ventricular septal defect (VSD). Neonates with transposition and VSD have been shown to have a native pulmonary valve and root that is significantly larger as compared to normal neonatal controls, and those with transposition with intact ventricular septum [14].

The purpose of this study was to evaluate the incidence of this neo-aortic regurgitation and the risk factors associated with its occurrence after the ASO.

\section{Patients and Methods}

All patients undergoing the ASO at the All India Institute of Medical Sciences, New Delhi, for simple transposition or transposition with ventricular septal defect (VSD) or double outlet right ventricle with sub pulmonic VSD, by two surgeons (ST, SKC) between January 2005 and December 2015 were retrospectively reviewed. Their detailed medical records and follow up echocardiograms were studied with special reference to the fate of their neo-aortic valve and ventricular function. The study protocol was duly approved by the ethics committee of the institute.

Patients' medical records including discharge summaries were reviewed to determine demographic details, including age and weight at the time of ASO, coronary artery anatomy according to Leiden convention, presence or absence of VSD, presence of associated cardiac anomalies like coarctation of aorta, interrupted aortic arch, total anomalous pulmonary venous connection, left ventricular outflow tract obstruction (LVOTO), need for pre-operative balloon atrial septostomy, size discrepancy between the aorta and pulmonary artery before ASO and abnormal coronary artery patterns [15]. Simple TGAs were defined as those with intact ventricular septum and left ventricle to aorta pulmonary artery gradient less than $50 \mathrm{~mm} \mathrm{Hg}$ [9].

Complex TGAs were defined as those with ventricular septal defect, or significant LVOTO or with aortic arch obstruction.

Aorto pulmonary discrepancy was said to be present if the size of the pulmonary annulus was 1.5 times more than the size of the aortic annulus. 2-D Echocardiography was performed using Philips iE33 x MATRIX cardiac ultrasound machine (Philips, Bothell, WI, USA). Neo-aortic regurgitation was quantitatively graded using Jenkin's criteria that take into account the width of colour jet at the level of the aortic valve and 1-2 mm, 3-4 mm, $4-6 \mathrm{~mm}$ and $>6 \mathrm{~mm}$ jet represented trivial, mild, moderate and severe AR respectively. Left ventricular systolic function was graded in terms of ejection fraction; > 55\% was accepted as normal function while $45-55 \%, 30-45 \%,<30 \%$ as mild, moderate and severe dysfunction respectively [16].

\section{Surgery and Anaesthesia}

Routine anaesthesia and surgical techniques were used. Intra-operative transesophageal echocardiography (TEE) was performed, wherever possible to confirm the diagnosis and to assess the left ventricular function and shape, any associated abnormality, shunting of the blood etc. Surgery was performed in the standard manner through a midline sternotomy. A pericardial patch was harvested and treated in $0.625 \%$ glutaraldehyde for 6 minutes for neo-pulmonary root reconstruction. All patients underwent primary ASO under moderately hypothermic (28 to $32^{\circ} \mathrm{C}$ ) cardiopulmonary bypass. Intravenous phenoxybenzamine $(1-2 \mathrm{mg} / \mathrm{kg}$ ) was infused slowly for uniform cooling purpose just before aortic cannulation.

Ventricular septal defects were closed mainly through the right atrium. In each case, the Lecompte maneuver was performed after the pulmonary trunk and aorta were transected above the semilunar valves. Coronary buttons were excised with a small part of aortic wall and relocated to the adjacent proximal part of the native pulmonary artery (neo-aorta) using the trap-door method, taking care to avoid distortion/kinking. Interposition of patches of autologous or prosthetic tissue can be used to overcome significant aorta-PA discrepancy but a "V" shaped reduction plasty was used in our cases to reduce discrepancy between neoaorta and pulmonary artery.

A patch of autologous fixed pericardium was used to fill the defect created by the harvesting of the coronary arteries and thus to reconstruct the sinus portion of the neo-pulmonary artery. Sternum was kept open, both pleural cavities were kept open, no pericardial or retrosternal tubes were placed. If hemodynamics were stable, the sternum was closed after 12-24 hours.

\section{Statistical Analysis}

Statistical analysis was performed using SPSS software version 23.0 (IBM Corp, Armonk, NY). Continuous variables were analysed using student 't-test' while categorical variables were analysed using two tailed chi square test. A P value of $<0.05$ was considered statistically significant.

\section{Results}

After reviewing patient records, 310 children who underwent ASO fulfilled the inclusion criteria and 289 of them could be followed up. Mean follow up was $4.82 \pm 3.1$ years (median 4 years; range 1-11 years). There were 233 (80.6\%) male and 56 (19.4\%) female patients. Mean weight at operation was $3.5 \pm 0.25 \mathrm{~kg}$; median of $3.2 \mathrm{~kg}$ (range $2.4 \mathrm{~kg}-11 \mathrm{~kg}$ ) and mean age at operation was $2.55 \pm 2.60$ months, median was 2 months (range 10 days17 months). 131 children had an associated VSD, and rest 158 had an IVS. Other complex congenital anomalies were present in small number of patients LVOTO in 13 patients, Co A in 2 patients, TAPVC in 1 patient and abnormal coronary artery pattern in 29 
patients. 18 patients had undergone balloon atrial septostomy prior to undergoing ASO. Pre-operative characteristics are shown in Table 1.

\begin{tabular}{|c|c|c|}
\hline \multirow{2}{*}{ Age at operation } & Age $<1$ month & 135 (46.7\%) \\
\hline & Age $>1$ month & $154(53.2 \%)$ \\
\hline $\begin{array}{c}\text { Mean weight at } \\
\text { operation }\end{array}$ & & 0.25 \\
\hline \multirow{3}{*}{ Presence of VSD } & VSD & $131(45.3 \%)$ \\
\hline & IVS & $139(48 \%)$ \\
\hline & TB & $19(6.5 \%)$ \\
\hline \multirow{2}{*}{ Sex } & Males & $233(80.6 \%)$ \\
\hline & Females & $56(19.3 \%)$ \\
\hline \multirow{4}{*}{$\begin{array}{c}\text { Associated } \\
\text { cardiac } \\
\text { malformations }\end{array}$} & LVOTO & $13(4.4 \%)$ \\
\hline & Taussig bing & $19(6.5 \%)$ \\
\hline & Coarctation of Aorta & $2(0.7 \%)$ \\
\hline & TAPVC & $1(0.4 \%)$ \\
\hline \multirow{2}{*}{$\begin{array}{c}\text { other pre-op } \\
\text { characteristics }\end{array}$} & Ao PA discrepancy & $24(8.3 \%)$ \\
\hline & BAS & $18(6.2 \%)$ \\
\hline
\end{tabular}

VSD-ventricular septal defect; IVS-intact ventricular septum; TB Taussig-Bing; LVOTO-left ventricular outflow tract obstruction; TAPVC-total anomalous pulmonary vein connection; Ao-aorta; PApulmonary artery; BAS-balloon atrial septostomy

At the last follow up, 35 patients (12.1\%) had developed neo-aortic regurgitation. Twenty-four had trivial AR and 10 had mild AR while only 1 patient had moderate AR; none developed severe AR. All patients had normal left ventricular function at last follow-up. Although not a part of our sample population, one patient who underwent ASO 20 years back at another institution developed severe neo-aortic regurgitation and underwent aortic valve replacement during the study period.

On univariate analysis, complex TGA (presence of VSD, associated abnormalities like TAPVC, arch anomalies) was found to be a risk factor for neo-aortic regurgitation. Presence of LVOTO, pre-operative aorta-pulmonary artery size discrepancy and abnormal coronary artery anatomy were also significant risk factors for neo-aortic regurgitation. Age at operation, sex of the patient and need for pre-operative balloon atrial septostomy (BAS) were not significant risk factors. On multi-variate logistic regression analysis, presence of VSD, LVOTO, abnormal coronary artery anatomy and Aorta -pulmonary artery size discrepancy were significantly associated risk factors for neo-aortic regurgitation. Statistical significance of various parameters is shown in Tables 2 and 3.

\section{Discussion}

\section{Incidence of $\mathbf{A R}$}

In 1988, medium term follow-up of twenty patients undergoing ASO was published by Martin, et al [17]. Eight patients (40\%) were shown to have various degrees of AR by Doppler echocardiography or cardiac catheterization, or both. This medium-term study indicated that trivial or mild AR is a frequent finding after anatomic correction of transposition of the great arteries. However, it rarely results in an audible cardiac murmur or significant left ventricular volume overload.

In a retrospective review of 324 hospital survivors after ASO, Walter et al reported that after a mean follow-up time of $14.4 \pm 0.54$ years, AR was absent in 307 (94.7\%), trivial in six $(1.8 \%)$, mild in nine $(2.7 \%)$, and moderate-to-severe in two $(0.6 \%)$ patients [10]. Two of their patients underwent aortic valve replacement at a mean time of 10.82 years after ASO. They concluded that AR is not rare after ASO, but it is stable without progressive intensity; new AR developed in $5.2 \%$ after 10 years, and is present only in $2.7 \%$ after a median follow-up $14.4 \pm 0.54$ years. If trivial AR is excluded, it is present only in $0.9 \%$. New AR can develop even up to 15 years. However, severe AR and need for AVR are rare.

Similarly, Jhang et al found a very low incidence of neoaortic regurgitation after ASO (neo-AR greater than Grade II was observed in only six of 240 patients $(2.5 \%)$ at a median follow-up duration of 79 months) and showed that neither the bicuspid pulmonary valve nor the trap-door technique were co-related with the occurrence of neo-AR [18]. They suggested that maintaining the sino-tubular junction (STJ) z-score and the ratio of STJ annulus can be a more critical factor than other perioperative factors in preventing neo-AR.

On the contrary, some groups have shown a relatively high incidence of AR. In a study by Nogi, et al, neo-aortic regurgitation has been described in 30\% patients at less than six years after surgery [5]. Hwang et al have found neo-AR to be present in 51\% patients in their cohort of 103 patients followed up for 77 months [19]. Our results are comparable to Losay 9 et al who noted $14.9 \%$ incidence of neo-aortic regurgitation with a similar period of follow up. We found a $12.1 \%$ incidence of neo-aortic regurgitation after a mean follow up of 4.82 years of follow-up, which is low but cannot be ignored as it can lead to significant morbidity in longterm; this mandates regular follow-up. 
Table 2: Risk factors for Neo AR (Patient characteristics)

\begin{tabular}{|c|c|c|c|c|c|c|}
\hline Variable & Without AR & With AR & p value & $\begin{array}{c}\text { Unadjusted odds } \\
\text { ratio (95\%C.I.) }\end{array}$ & $\begin{array}{l}\text { Adjusted odds } \\
\text { ratio }\end{array}$ & $P$ value \\
\hline Age $<1$ month & 121 (89.6\%) & $14(10.4 \%)$ & \multirow[t]{2}{*}{0.396} & 1 & - & \multirow[t]{2}{*}{ - } \\
\hline Age $>1$ month & $133(86.4 \%)$ & $21(13.6 \%)$ & & $1.36(0.66,2.80)$ & - & \\
\hline Male sex & 206 (88.4\%) & 27 (11.6\%) & \multirow[t]{2}{*}{0.578} & 1 & 1 & \multirow[t]{2}{*}{0.09} \\
\hline Female sex & 48 (85.7\%) & $8(14.3 \%)$ & & $0.786(0.34,1.8)$ & $\begin{array}{c}0.345 \\
(0.09,1.2)\end{array}$ & \\
\hline $\begin{array}{l}\text { TGA undergoing BAS } \\
\text { before ASO }\end{array}$ & $16(88.9 \%)$ & $2(11.1 \%)$ & \multirow[t]{2}{*}{0.893} & 1 & & \multirow[t]{2}{*}{ - } \\
\hline No pre BAS & $238(87.8 \%)$ & 33 (12.2\%) & & $0.9(0.19,4.09)$ & & \\
\hline
\end{tabular}

AR-aortic regurgitation, TGA-transposition of great arteries; BAS-balloon atrial septostomy; ASO-arterial switch operation

Table 3: Risk factors-anatomical

\begin{tabular}{|c|c|c|c|c|c|c|}
\hline Variable & Without AR & With AR & p value & $\begin{array}{l}\text { Unadjusted odds } \\
\text { ratio (95\%C.I.) }\end{array}$ & Adjusted odds ratio & $P$ value \\
\hline TGA with VSD & $102(87.9 \%)$ & $29(22.1 \%)$ & \multirow[t]{2}{*}{$<0.001$} & $7.2(2.89,17.97)$ & $4.07(1.27,13.05)$ & \multirow[t]{2}{*}{0.01} \\
\hline TGA with IVS & $152(96.2 \%)$ & $6(3.8 \%)$ & & 1 & 1 & \\
\hline TGA with DORV & $13(68.4 \%)$ & $6(31.6 \%)$ & \multirow[t]{2}{*}{0.007} & $3.83(1.35,10.86)$ & - & \multirow[t]{2}{*}{-} \\
\hline TGA without DORV & $241(89.2 \%)$ & $29(10.7 \%)$ & & 1 & - & \\
\hline TGA with LVOTO & $6(46.1 \%)$ & $7(53.9 \%)$ & \multirow[t]{2}{*}{$<0.001$} & $10.33(3.24,32.9)$ & $10.23(1.92,54.53)$ & \multirow[t]{2}{*}{0.06} \\
\hline TGA without LVOTO & $248(89.9 \%)$ & $28(10.1 \%)$ & & 1 & 1 & \\
\hline TGA-CoA/Arch anomalies & 0 & $2(100 \%)$ & \multirow[t]{2}{*}{$<0.001$} & - & - & \\
\hline $\begin{array}{l}\text { TGA without } \mathrm{CoA} / \mathrm{Arch} \\
\text { anomalies }\end{array}$ & $\begin{array}{c}254 \\
(88.55 \%) \\
\end{array}$ & $33(11.5 \%)$ & & - & - & \\
\hline $\begin{array}{l}\text { TGA with associated } \\
\text { TAPVC }\end{array}$ & 0 & $1(100 \%)$ & \multirow[t]{2}{*}{0.007} & - & - & \\
\hline $\begin{array}{l}\text { TGA without associated } \\
\text { TAPVC }\end{array}$ & $254(88.2 \%)$ & $34(11.5 \%)$ & & - & - & \\
\hline $\begin{array}{l}\text { TGA with Ao PA } \\
\text { discrepancy }\end{array}$ & $5(20.8 \%)$ & $19(79.2 \%)$ & $<0.001$ & $\begin{array}{c}59.13 \\
(19.54,178.9)\end{array}$ & $\begin{array}{c}42.28 \\
(11.0,162.3)\end{array}$ & $<0.001$ \\
\hline $\begin{array}{l}\text { TGA without Ao PA } \\
\text { discrepancy }\end{array}$ & $249(93.9 \%)$ & $16(6.1 \%)$ & & 1 & 1 & \\
\hline $\begin{array}{l}\text { TGA with most common } \\
\text { coronary pattern }\end{array}$ & $242(93.1 \%)$ & $18(6.9 \%)$ & $<0.001$ & 1 & 1 & $<0.001$ \\
\hline $\begin{array}{l}\text { TGA with abnormal } \\
\text { coronary pattern }\end{array}$ & $12(41.4 \%)$ & $17(58.6 \%)$ & & $\begin{array}{c}19.04 \\
(7.89,45.94)\end{array}$ & $\begin{array}{c}15.98 \\
(4.68,54.58)\end{array}$ & \\
\hline
\end{tabular}




\section{Need for AVR}

To date, the need for AVR is still rare after ASO and is estimated around $1.4 \%$ by Formigari, et al, $1.4 \%$ by Losay et al, $2.4 \%$ by Schwartz, et al and $2.3 \%$ by Lange, et al $[20,21,8,9]$. None of our patients required AVR, probably due to relatively shorter follow up. Although incidence of AVR is very low, but it at least warrants constant follow up because it is not late since first ASO was performed and more and more patients might present with severe AR in future.

\section{Risk factors of AR}

The aetiology of AR after ASO is multifactorial and different risk factors have been identified in different studies. Aortic root dilatation is a common finding after the ASO, but no consistent correlation with the occurrence of AR has been found by Hutter, et al and Formigiri, et al [21,11]. Only few studies could demonstrate that patients with aortic root dilatation had a higher risk of developing AI, although AI was mostly trivial to mild. Measurement of aortic root dimension was not performed in our study because of lack of reliable preoperative retrospective information, and therefore the role of root dilation in the development of AR was not investigated.

Mc Mohan, et al studied 119 patients (44 females and 75 males): 73 patients had simple d-TGA, 36 had d-TGA with ventricular septal defect, and 10 had a Taussig-Bing heart [22]. The median duration of follow up was 65 months (range, 12180). Development of severe neo-aortic root enlargement was associated with prior pulmonary artery banding ( $\mathrm{p}<0.01$ ), the presence of a VSD ( $p=0.03)$, and Taussig-Bing anatomy ( $p<0.01$ ) but was independent of coronary arterial anatomy, coronary arterial transfer technique, or associated lesions $(\mathrm{p}>$ 0.05). At latest follow-up, there was no or trivial AR in 88 patients, mild AR in 29 patients, and moderate to severe AR in 3 patients.

Michalak, et al followed 519 for 10 years and observed that the frequency of significant regurgitation increased from $9 \% 1$ year after the operation to $47 \%$ at the most recent follow-up [23]. No severe regurgitation necessitating reoperation was observed. Analysis of potential risk factors revealed that pulmonary/ aortic valve diameter discrepancy and non-facing commissures were associated with increased risk of development of neoaortic insufficiency. Neo-AR arises and develops over time after correction of the defect.

Jenkins et al16 found higher incidence (41\%) of neoaortic regurgitation after reviewing 112 patients of ASO but again most of them had only trivial to mild regurgitation. They found patients having prior PA banding significantly increased the risk of neo aortic regurgitation after two-stage ASO but our patients mostly underwent single stage ASO, this factor was not studied. Interestingly, in their experience, patients with intact ventricular septum had a higher incidence of regurgitation but in our study, complex TGA patients had higher regurgitation after ASO.
Mohammadi, et al showed that VSD closure through the pulmonary valve increased the risk of developing AR in the longterm [24]. But most of our patients had VSD closure performed through right atrial approach. Despite this, presence of VSD was independent risk factor for AR on multivariate analysis. This was explained by Losay, et al to be due to pulmonary root dilatation caused by VSD by increasing PA pressures and also by increasing flow across it [25].

In 2006, Losay et al presented long term fate of aortic valve after ASO in a large cohort of 1156 hospital survivors with a mean follow up of 76.2 months and found $14.9 \%$ patients had neoaortic regurgitation [25]. Complex TGA, prior PA banding, aortic arch anomalies, AR at discharge, older age at ASO, aortic/pulmonary artery size discrepancy were associated with AR. These findings are comparable to ours such that late aortic valve function warrants long term monitoring. They found that prevalence of AR increased over time but degree of AR may actually decrease with follow up.

In a study by Formigari11 et al, the trap-door type of coronary reimplantation is associated with an increased risk for valvular dysfunction, possibly because of a distortion of the sinotubular junction geometry but coronary artery anatomy was not found to be a significant risk factor for AR by Lange et al [20]. Previous PA band and bicuspid pulmonary valve have also been incriminated in increased development of neoaortic regurgitation by Gibbs, et al and Keane, et al respectively [12,13]. Another common association has been ventricular septal defect as shown by Houriha, et al, neonates with transposition and ventricular septal defect had a native pulmonary valve and root that was significantly larger than in normal neonatal controls, and also than in neonates with transposition with intact ventricular septum [14].

\section{Progression of AR}

Progressive increase in neoaortic regurgitation has been reported by Imamura et al, Yoshizumi et al, and Schwartz, et al [68]. In Lange's retrospective review of 479 hospital survivors after ASO, $15 \%$ patients had AR at the time of discharge progressing to $20.1 \%$ after 1 year and after mean follow up of 9.3 years, only $53 \%$ patients were free from AR [20]. This incidence is much more than ours but their follow up was longer. Patients with VSD or Taussig-Bing anomaly were found to be at a higher risk of AR which is also evident in our study. Progression of AR was not evaluated in our study due to lack of reliable preoperative retrospective information.

\section{Conclusion}

Incidence of aortic regurgitation after arterial switch operation remains low and need of aortic valve replacement is rare. In our experience, development of aortic regurgitation is related to presence of complex type of TGAs, pre-operative aorta pulmonary size discrepancy and abnormal coronary artery anatomy. 


\section{References}

1. Jatene AD, Fontes VF, Paulista PP, Souza LCB, Neger F, Galantier M, et al. Anatomic correction of transposition of the great vessels. J Thorac Cardiovasc Surg. 1976;72(3):364-370

2. Boenhoffer P, Bonnet D, Piechaud JF, Stumper O, Aggoun Y, Villain E, et al. Coronary artery obstruction after arterial switch operation for transposition of the great arteries in newborns. J Am Coll Cardiol. 1997;29(1):202-206

3. Martin MM, Snider AR, Bove EL, Serwer GA, Rosenthal A, Peters J, et al. Two-dimensional and Doppler echocardiographic evaluation after arterial switch repair in infancy for complete transposition of the great arteries. Am J Cardiol. 1989;63(5):332-336

4. Williams WG, Quaegebeur JM, Kirklin JW, Blackstone EH. Outflow obstruction after the arterial switch operation: a multi institutional study. J Thorac Cardiovasc Surg. 1997;114(6):975-990. doi: 10.1016/ S0022-5223(97)70012-6

5. Nogi S, McCrindle BW, Boutin C, Williams WG, Freedom RM, Benson LN. Fate of the neopulmonary valve after the arterial switch operation in neonates. J Thorac Cardiovasc Surg. 1998;115(3):557-562. doi: 10.1016/S0022-5223(98)70317-4

6. Imamura M, Drummond-Webb JJ, McCarthy JF, Mee RBB. Aortic valve repair after arterial switch operation. Ann Thorac Surg. 2000; 69(2): 607-608

7. Yoshizumi K, Yagihara T, Uemura H. Approach to the neo-aortic valve for replacement after the arterial switch operation in patients with complete transposition. Cardiol Young. 2001; 11(6): 666-669

8. Schwartz ML, Gauvreau K, del Nido P, Mayer JE, Colan SD. Long-term predictors of aortic root dilation and aortic regurgitation after arterial switch operation. Circulation. 2004;110(11 Suppl 1): II128-II32. doi: 10.1161/01.CIR.0000138392.68841.d3

9. Losay J, Touchot A, Serraf AL, V Lambert, JD Piot, F Lacour-Gayet, et al. Late outcome after arterial switch operation for transposition of the great arteries. Circulation. 2001;104(suppl): I121-I126. doi: 10.1161/ hc37t1.094716

10. Walter EMD, Huebler M, Meshkishvili VA, Sill B, Berger F, Hetzer R. Fate of the aortic valve following the arterial switch operation. J Card Surg. 2010;25(6):730-736. doi: 10.1111/j.1540-8191.2010.01144.x

11. Formigari R, Toscano A, Giardini A, Gargiulo G, Donarto RD, Picchio FM, et al. Prevalence and predictors of neoaortic regurgitation after arterial switch operation for transposition of great arteries. J Thorac Cardiovasc Surg. 2003;126(6):1753-1759. doi: 10.1016/S0022

12. Gibbs JL, Qureshi SA, Martin R, Wilson N, Yacoub MH, Smith RR. Neonatal anatomical correction of transposition of the great arteries: non-invasive assessment of haemodynamic function up to four years after operation. Br Heart J. 1988;60(1):66-68. doi: 10.1136/ hrt.60.1.66

13. Keane MG, Wiegers SE, Plappert T, Pochettino A, Bavaria JE, St. John Sutton MG. Bicuspid aortic valves are associated with aortic dilatation out of proportion to coexistent valvular lesions. Circulation. 2000;
102(19 Suppl 3):III35- III39

14. Hourihan M, Colan SD, Wernovsky G, Maheswari U, Mayer JE, Sanders SP. Growth of the aortic anastomosis, annulus and root after the arterial switch procedure performed in infancy. Circulation. 1993;88(2):615620

15.Gittenberger-de Groot, A Sauer U, Oppenheimer-Dekker, A, Quaegebeur, J. Coronary arterial anatomy in transposition of the great arteries: a morphologic study. Pediatr Cardiol. 1983;4:15-24

16. Jenkins KJ, Hanley FL, Colan SD, Mayer JE Jr, Castañeda AR, Wernovsky G. Function of the anatomic pulmonary valve in the systemic circulation. Circulation. 1991;84(5 Suppl):III173- III179

17. Martin RP, Ettedgui JA, Qureshi SA, Gibbs JL, Baker EJ, Smith RR, et al. A quantitative evaluation of aortic regurgitation after anatomic correction of transposition of great arteries. J Am Coll Cardiol. 1988;12(5):1281-1284

18. Jhang WK, Shin HJ, Park JJ, Yun TJ, Kim YH, Ko JK, et al. The importance of neo-aortic root geometry in the arterial switch operation with the trap door technique in the subsequent development of aortic valve regurgitation. Eur J cardiothorac Surg. 2012;42(5):794-799. doi: 10.1093/ejcts/ezs169

19. Hwang HY, Kim WH, Kwak JG, Lee JR, Kim YJ, Rho JR, et al. Midterm follow-up of neoaortic regurgitation after the arterial switch operation for transposition of the great arteries. Eur J Cardiothorac Surg. 2006;29(2):162-167. doi: 10.1016/j.ejcts.2005.11.027

20. Lange R, Cleuziou J, Hörer J, Holper K, Vogt M, Tassani-Prell P, et al. Risk factors for aortic insufficiency and aortic valve replacement after the arterial switch operation. Eur J Cardiothorac Surg. 2008;34(4):711717. doi: 10.1016/j.ejcts.2008.06.019

21. Hutter PA, Thomeer BJM, Jansen P, Hitchcock JF, Faber JAJ, Mejboom EJ, et al. Fate of the aortic root after the arterial switch operation. Eur J Cardiothorac Surg. 2001;20:82-88

22. McMahon CJ, Ravekes WJ, Smith EO, Denfield SW, Pignatelli RH, Altman CA, et al. Risk Factors for Neo-Aortic Root Enlargement and Aortic Regurgitation Following Arterial Switch Operation. Pediatr Cardiol. 2004;25(4):329-335. doi: 10.1007/s00246-003-0483-6

23. Michalak KW, Moll JA, Moll M, Mludzik K, Moll JJ. Neoaortic Valve Function 10 to 18 Years after Arterial Switch Operation. World J Pediatr Congenit Heart Surg. 2010;1(1):51-58. doi: $10.1177 / 2150135110361361$

24. Mohammadi S, Serraf A, Belli E, Aupecle B, Capderou A, Lacour-Gayet $\mathrm{F}$, et al. Left-sided lesions after anatomic repair of transposition of the great arteries, ventricular septal defect, and coarctation: surgical factors. J Thorac Cardiovasc Surg. 2004;128(1):44-52. doi: 10.1016/j. jtcvs.2004.01.040

25. Losay J, Touchot A, Capderou A, Piot JD, Belli E, Planche C, et al. Aortic valve regurgitation after arterial switch operation for transposition of the great arteries: incidence, risk factors, and outcome. J Am Coll Cardiol. 2006;47(10):2057-2062. doi: 10.1016/j.jacc.2005.12.061 